\title{
Identification of Candidate Genes for Alcohol Preference by Expression Profiling of Congenic Rat Strains
}

\author{
Lucinda G. Carr, Mark W. Kimpel, Tiebing Liang, Jeanette N. McClintick, Kevin McCall, \\ Melissa Morse, and Howard J. Edenberg \\ Departments of Medicine, Biochemistry and Molecular Biology, and Psychiatry, Indiana University \\ School of Medicine, Indianapolis, Indiana
}

\section{Abstract}

Background-A highly significant quantitative trait locus (QTL) on chromosome 4 that influenced alcohol preference was identified by analyzing crosses between the iP and iNP rats. Congenic strains in which the iP chromosome 4 QTL interval was transferred to the iNP (NP.P) exhibited the expected increase in alcohol consumption compared with the iNP background strain. This study was undertaken to identify genes in the chromosome 4 QTL interval that might contribute to the differences in alcohol consumption between the alcohol-naïve congenic and background strains.

Methods-RNA from 5 brain regions from each of 6 NP.P and 6 iNP rats was labeled and analyzed separately on an Affymetrix Rat Genome 2302.0 microarray to look for both cisregulated and trans-regulated genes. Expression levels were normalized using robust multi-chip average (RMA). Differential gene expression was validated using quantitative real-time polymerase chain reaction. Five individual brain regions (nucleus accumbens, frontal cortex, amygdala, hippocampus, and striatum) were analyzed to detect differential expression of genes within the introgressed QTL interval, as well as genes outside that region. To increase the power to detect differentially expressed genes, combined analyses (averaging data from the 5 discrete brain regions of each animal) were also carried out.

Results-Analyses within individual brain regions that focused on genes within the QTL interval detected differential expression in all 5 brain regions; a total of 35 genes were detected in at least 1 region, ranging from 6 genes in the nucleus accumbens to 22 in the frontal cortex. Analysis of the whole genome detected very few differentially expressed genes outside the QTL. Combined analysis across brain regions was more powerful. Analysis focused on the genes within the QTL interval confirmed 19 of the genes detected in individual regions and detected 15 additional genes. Whole genome analysis detected 1 differentially expressed gene outside the interval.

Conclusions-Cis-regulated candidate genes for alcohol consumption were identified using microarray profiling of gene expression differences in congenic animals carrying a QTL for alcohol preference.

Copyright (๑) 2007 by the Research Society on Alcoholism

Reprint requests: Lucinda G. Carr, PhD, Departments of Medicine and Pharmacology, Indiana University School of Medicine, Medical Research and Library Building, Room 407, 975 W. Walnut Street, Indianapolis, IN 46202; Fax: 317-274-2695; lcarr@iupui.edu. 


\section{Keywords}

Alcohol Consumption; QTL; Microarray; Candidate Genes; Congenic Rats

Genes Contributing to alcoholism are difficult to identify due to both the genetic complexity of alcoholism and environmental variability among alcoholic subjects. While various techniques can be utilized to identify possible molecular and physiological patterns associated with alcoholism, localizing the primary genetic determinants for the risk to develop alcoholism has proven to be difficult. Nevertheless, several genes have been associated with a risk for alcoholism in studies that have been replicated, e.g. GABRA2 (Covault et al., 2004; Edenberg et al., 2004; Fehr et al., 2006; Lappalainen et al., 2005), ADH4 (Edenberg et al., 2006; Guindalini et al., 2005; Luo et al., 2005a), and CHRM2 (Luo et al., 2005b; Wang et al., 2004). It is evident, however, that there are other genes that also influence the risk for alcoholism. Selective breeding of rodents for alcohol-related traits, followed by quantitative trait locus (QTL) analysis has located genomic regions in which variation affects the phenotype. However, finding the specific genes within such regions is difficult. A strategy of making congenic animal models carrying a single QTL, and then using microarray analysis to determine which genes are altered in expression, should provide a powerful approach toward gene identification (Hitzemann et al., 2004; Hoffman and Tabakoff, 2005; Spence et al., 2005). Using this combined approach dramatically decreases the number of genes that are expected to be differentially expressed because the 2 strains are identical except for the QTL sequences, thereby increasing the probability to identify differentially expressed genes contributing to a specific phenotype such as alcohol preference.

The alcohol-preferring (P) and alcohol-nonpreferring (NP) rat lines were developed, through bidirectional selective breeding, from a randomly bred, closed colony of Wistar rats, on the basis of alcohol preference in a 2-bottle choice paradigm (Li et al., 1991). Alcoholpreferring rats display the phenotypic characteristics considered necessary for an animal model of alcoholism (Cicero, 1979; Li et al., 1993). Subsequently, inbred P (iP) and NP (iNP) strains were established; these inbred strains maintain highly divergent alcohol consumption scores (Carr et al., 1998). Owing to the physiological and genetic similarity between humans and rats, iP and iNP rats can be studied to identify important genetic factors that might influence alcoholic predisposition in humans.

A highly significant QTL that influenced alcohol preference was identified on chromosome 4 (with a maximum lod score of 9.2) in a cross between iP and iNP rats; suggestive QTLs were identified on chromosomes 3 and 8 (Bice et al., 1998; Carr et al., 1998). The chromosome 4 QTL acts in an additive fashion and accounts for approximately $11 \%$ of the phenotypic variability. Owing to the strong association between the chromosome 4 QTL region and alcohol preference, this approximately $25 \mathrm{cM}$ region is likely to harbor at least 1 gene that directly contributes to alcohol preference. Reciprocal congenic strains in which the iP chromosome 4 QTL interval was transferred to the iNP (NP.P) and the iNP chromosome 4 QTL interval was transferred to the iP (P.NP) exhibited the expected effect on alcohol consumption of the strain that donated the chromosome 4 QTL interval (Carr et al., 2006). 
This indicates that the chromosome 4 QTL region is, in part, responsible for the disparate alcohol consumption observed between the iP and iNP rats.

The objective of the present study was to identify genes in the chromosome 4 QTL interval that might be responsible for the divergent alcohol preference of the iNP and iP strains. Because the chromosome 4 QTL interval is the only region that differs between the 2 strains, analyzing only the probe sets in this interval focuses on the cis-regulated genes, and increases power by reducing the number of comparisons. Analysis of all the probe sets allows detection of both cis-regulated and trans-regulated genes, but at the expense of testing more probe sets [and therefore a higher false discovery rate (FDR) and lower power]. Discrete brain regions were analyzed for expression differences between the homozygous NP.P and the iNP background strain, to detect differences that might be localized to 1 region. Expression data from the 5 brain regions of each animal were then combined to obtain an average expression level for analysis of genes that may differ across multiple regions; combining the 5 regions in a single animal reduces technical variation and should increase power to detect differences that are in the same direction but that may fall below significance in individual regions. These complementary analyses should allow us to better understand the inherent differences in gene expression between strains that differ in alcohol preference as a result of genetic differences in a single chromosomal region.

\section{MATERIALS AND METHODS}

\section{Animals}

Creation of the NP.P congenic strain has been described previously (Carr et al., 2006). Briefly, the NP.P congenic strain was initiated by crossing 1 male rat from the iP5 strain with 1 female rat from the iNP1 strain to create iPiNP F1 animals, which were backcrossed to the iNP1 strain to produce the N2 generation. The presence of the chromosome 4 interval was confirmed using microsatellite markers. Ten generations of backcrossing to the iNP1 strain were performed, followed by an intercross between N10 animals to produce homozygous animals (N10F1), which resulted in the finished congenic strain.

All animals were individually housed on a standard 12 hour: 12 hour light:dark cycle and were provided nutritionally balanced rat chow and water ad libitum. Animals were habituated (by the same experimenter) to handling and to the guillotine daily between 09:00 and 10:00 hours for 10 days before being killed. The animals used in these experiments were maintained in facilities fully accredited by the Association for the Assessment and Accreditation of Laboratory Animal Care (AAALAC). All research protocols were approved by the Institutional Animal Care and Use Committee and are in accordance with the guidelines of the Institutional Animal Care and Use Committee of the National Institute on Drug Abuse, NIH, and the Guide for the Care and Use of Laboratory Animals (Institute of Laboratory Animal Resources, Commission on Life Sciences, National Research Council, 1996).

A total of 12 (6 iNP and 6 NP.P) male rats, 14 to 15 weeks of age, were killed by decapitation between 09:00 and 10:00 hours over 2 consecutive days, with equal numbers of animals from each strain killed each day. This minimized differences in time of killing and 
dissection, and maintained the experimental balance across the 2 strains. The head was immediately immersed in chilled isopentane $\left(-50^{\circ} \mathrm{C}\right)$ for 15 seconds and then placed in a cold box maintained at $-15^{\circ} \mathrm{C}$, where the brain was rapidly removed and placed on a glass plate for dissection. All equipment used to obtain tissue was treated with RNaseZap (Ambion Inc., Austin, TX) to prevent RNA degradation. The nucleus accumbens, caudate putamen, frontal cortex, hippocampus, and amygdala were dissected as described previously (Liang et al., 2004).

\section{RNA Isolation}

Dissected tissues were immediately homogenized in Trizol reagent (Invitrogen, Carlsbad, CA) and processed according to the manufacturer's protocol, but with triple the suggested ratio of Trizol to tissue (Edenberg et al., 2005). Ethanol-precipitated RNA was further purified through RNeasy ${ }^{\circledR}$ midi columns (Qiagen, Valencia, CA), according to the manufacturer's protocol. To avoid DNA contamination in the real-time polymerase chain reaction (PCR) assay, the RNA was treated with $1 \mathrm{U}$ of DNase I for 20 minutes at $37^{\circ} \mathrm{C}$. Total RNA yields in each region did not differ between the congenics and the iNP animals ( $p>0.47$ ); the average yields in the different regions ranged from 69 to $97 \mu \mathrm{g}$. The quality of the RNA from all rats and regions was similar, as monitored by absorbance spectra from 210 to $350 \mathrm{~nm}$, by electrophoresis on 1\% agarose gels, and using an Agilent Bioanalyzer (Agilent Technologies, Santa Clara, CA) to confirm the ribosomal bands.

\section{RNA Labeling and Microarray Hybridization}

RNA from each individual rat was labeled and hybridized separately on an Affymetrix Rat Genome 2302.0 microarray. Starting with $5 \mu \mathrm{g}$ of total RNA from each animal, first and second-strand cDNA synthesis was carried out according to the standard protocols from Affymetrix (Affymetrix: GeneChip ${ }^{\circledR}$ Expression Analysis Technical Manual, Santa Clara, CA, Affymetrix, 2001). Biotinylated cRNA was synthesized in vitro from the doublestranded cDNA using the ENZO BioArray High Yield RNA Transcript Labeling Kit (ENZO Diagnostics, Farmingdale, NY) according to the Affymetrix protocol. Fifteen micrograms of fragmented, biotinylated cRNA was mixed into $300 \mu \mathrm{L}$ of hybridization cocktail, of which $200 \mu \mathrm{L}$ was used for each hybridization. Hybridization was carried out for 17 hours at $42{ }^{\circ} \mathrm{C}$. Washing, staining, and scanning were carried out according to the standard protocol.

To minimize potential systematic errors, all stages of the experiment were balanced across phenotypes. That is, equal numbers of NP.P and iNP animals were killed each day, and equal numbers of RNA preparations from iP and iNP animals were processed through the labeling, hybridization, washing, and scanning protocols on each day, in different alternating orders. Whenever possible, common premixes of reagents were used to minimize effects due to differences in reagent preparation.

\section{Data Analysis and Informatics}

Each GeneChip ${ }^{\circledR}$ was scanned using an Affymetrix Model 3000 scanner and underwent image analysis using Affymetrix GCOS software. Microarray data are available from the National Center for Biotechnology Information's Gene Expression Omnibus, http:// www.ncbi.nlm.nih.gov/geo/ (Barrett et al., 2005; Edgar et al., 2002) under series Accession 
No. GSE5849 (GSM136446 ... GSM136505). Raw .cel files were imported into the statistical programming environment R (R Development Core Team, 2006) for further analysis with tools available from the Bioconductor Project (Gentleman et al., 2004). Expression data were normalized and $\log _{2}$ transformed using the robust multichip average (RMA) method (Bolstad et al., 2003; Irizarry et al., 2003) implemented in the Bioconductor package RMA.

Mapping of probe sets to chromosomal locations was accomplished with data provided by Affymetrix. The identities of the probe sets were confirmed by comparing the target mRNA sequences on the Affymetrix Rat Genome 230 2.0 GeneChip with the NCBI nucleotide databases. Any probe set that could not be annotated was culled from the list, leaving 28,049 probe sets for further analysis. To increase power and decrease the FDR, probe sets were subjected to further filtering to remove those probe sets not reliably detected by the arrays (McClintick and Edenberg, 2006). Using the detection call generated by the Affymetrix Microarray Analysis Suite 5.0 algorithm, probe sets were retained that had a fraction present of at least 0.33 in at least 1 group of samples in the comparison (McClintick and Edenberg, 2006). For the analyses by brain region, the probe sets were retained if probe sets had a fraction present $\geq 0.33$ for either the congenic NP.P or iNP animals for that brain region (20,300-21,800 probe sets for individual regions). For the analyses by average expression level, probe sets were used that had a fraction present $\geq 0.33$ for at least 1 brain region in at least 1 strain $(23,079$ probe sets).

Genewise $p$ values were calculated by $t$-tests performed using the package Limma (Smyth, 2004). False discovery rate was calculated by the method of Benjamini and Hochberg (1995). Probe sets were considered to be differentially expressed if the FDR was $<0.10$. First, each individual brain region was analyzed separately. Then, data from the 5 brain regions from each animal were averaged and the average value was analyzed to detect differences that were more general across multiple regions. To focus on cis-regulated genes, probe sets that mapped to the chromosome 4 QTL region between 29,413,686 and $128,186,835$ base pairs (4q13-4q34), locations of the microsatellite markers D4Rat151 and D4Rat55 that flanked the introgressed region, were analyzed separately (960 probe sets).

\section{Quantitative Real-Time PCR}

Quantitative real-time PCR (qRT-PCR) was carried out using SYBR Green chemistry and the ABI Prism 7700 sequence detection system (Applied Biosystems, Foster City, CA). The amplification primers were designed from the sequence in the coding region of the gene using Vector NTI (Invitrogen); when possible, at least 1 primer spanned an exon/intron boundary. Total RNA, isolated for the microarray analyses, was used for these analyses. Following reverse transcription of the RNA [Superscript III reverse transcription system for RT-PCR (Invitrogen)], an aliquot of each reverse transcription reaction was amplified in triplicate. The qRT-PCR was repeated to generate 6 values for each test sample. Two control reactions were run for each RNA preparation: (1) a reverse transcription and PCR reaction with no added RNA to control for contamination of the reagents and (2) a PCR reaction without the reverse transcription reaction to detect DNA contamination of the RNA preparation. To correct for sample-to-sample variation, an endogenous control (GAPDH) 
was amplified with the target and served as an internal reference to normalize the data. The average GAPDH $C_{\mathrm{t}}$ values for NP.P and iNP were the same in each brain region tested, making this an appropriate control gene to normalize the expression of the candidate genes of interest. Relative quantification of data from the ABI Prism 7700 sequence detection system was performed using the standard curve method (Applied Biosystems, User Bulletin \#2; http://www.appliedbiosystems.com).

\section{RESULTS}

\section{Cis-Regulated Genes}

Microarray analyses were performed to detect differences between the congenic NP.P and inbred NP (iNP) rats in gene expression in 5 brain regions (nucleus accumbens, frontal cortex, amygdala, hippocampus, and striatum). These regions were selected based on their inclusion in the mesolimbic and mesocortical systems, both of which are critically important in the initiation and maintenance of goal-directed and reward-mediated behaviors (reviewed in Bonci et al., 2003 and Maldonado, 2003). Because the only genetic differences between these 2 strains are in the QTL region on chromosome 4, examining just the set of genes located in this region allows the most powerful test of $c i s$-regulated candidate genes. More differences (at FDR $<0.10$ ) were detected in the frontal cortex, amygdala, and striatum, and the fewest differences in the nucleus accumbens (Table 1). Three genes differed in all 5 brain regions; these are not well annotated, but have some homology to known genes. Ppm1k_predicted [protein phosphatase $1 \mathrm{~K}$ (PP2C domain containing) (predicted)] was lower (about 2-fold) in all 5 regions in NP.P (Table 1). LOC685879 (similar to juxtaposed with another zinc finger protein 1) was higher (about 1.6-fold) in NP.P. RGD1304879 [similar to zinc finger protein 398 (binding protein p52/p71)] was higher (about 1.3-fold) in NP.P. Two genes, Snx 10 (sorting nexin 10, involved in intracellular trafficking) and Tsga13 [testis-specific gene A13 (predicted)] differed in 4 of the 5 regions, and were 1.5-fold higher and about 1.3-fold lower in NP.P, respectively. Two genes (Akr1b10 and Nfe213) each differed in 3 regions and another 10 differed in 2 of the regions. The direction of the differences is similar when comparing the NP.P and iNP.

To detect more widespread differences in gene expression, data from the 5 discrete brain regions of each animal were averaged. This reduces random technical variation from the individual extractions and labeling, and thereby provides more power to detect differences that are in the same direction in multiple regions but may fall below significance in individual regions. In the analysis focused on the chromosome 4 QTL region, 35 genes within the region differed between the 2 strains; 12 were lower in NP.P and the remaining 23 were higher in NP.P (Table 2). Most of the differences were small. Neuropeptide Y (Npy) and alpha synuclein (Snca), previously identified candidate genes for alcohol consumption in the iP and iNP rats (Liang et al., 2003; Spence et al., 2005), differed in expression in this combined analysis.

\section{Trans-Regulated Genes}

To detect trans-regulated genes (genes identical in the 2 strains that are differentially expressed due to variations in a regulatory gene located within the chromosome 4 region), 
we analyzed all of the probe sets on the array. This reduces the power to detect differences because the very large amount of additional testing increases the FDR. As would be expected when comparing the congenic strain with the background strain, nearly all of the probe sets that exhibited significant differences in expression between the NP.P and iNP were located in the chromosome 4 QTL interval. Some of the genes that were significant in the analysis of the chromosome 4 region alone no longer met the criteria of FDR $<0.10$. At an FDR <0.10, 6 differences were detected in amygdala, 8 in striatum, and 4 in the frontal cortex; none were detected in either nucleus accumbens or the hippocampus (Table 1). Only 4 trans-regulated genes were detected, 3 in the amygdala and 1 in the frontal cortex, and all were expressed at lower levels in the NP.P strain (Table 1).

In the combined analysis of the 5 brain regions using all probe sets, nearly all of the differences (34/35) were in genes located in the chromosome 4 region (Table 2). Some of the genes detected in our analysis of chromosome 4 probe sets alone no longer met FDR $<0.10$ when the larger number of comparisons was performed. The one trans-regulated gene that was detected, Sos1 (Son of sevenless homolog 1), is important in signal transduction.

The mapped locations of the transcripts and their direction of expression are shown in Fig. 1. We noticed that several clusters of adjacent genes were coordinately up-regulated or downregulated in the congenic animals. For example, except for RGD1306697, 9 transcripts that mapped between Plxna4 and RGD130487 were expressed more in the NP.P animals. Seven of the next 8 transcripts were expressed at lower levels in the NP.P.

\section{Confirmation by qRT-PCR}

To confirm genes that differed in expression between the NP.P and iNP, qRT-PCR was performed. Based on the literature reports of their possible involvement in pathways related to alcohol-seeking behavior, 9 genes were selected for confirmation. The first gene selected for confirmation was diacylglycerol kinase, iota ( $D g k i)$; all 5 brain regions were tested and the direction of expression was in the expected direction in all 5 regions. The remaining genes were tested in the striatum (Table 3). The differential expression of Akr1b4, Grid2, Baiapl, Dgki, Snca, and Ppmlk was confirmed at $p<0.005$ (Table 3). The expression of Sos 1 and Npy was in the expected direction.

\section{DISCUSSION}

The NP.P strain, with the iP Chr 4 QTL interval introgressed onto the iNP background, exhibits the expected increase in alcohol consumption compared with the iNP littermates (Carr et al., 2006). By examining gene expression in this congenic strain, we limited the differences expected to those originating from genetic variation within the QTL region shown to affect the phenotype of alcohol preference. This allowed us to identify candidate quantitative trait genes (QTGs) for the alcohol preference phenotype. Because the 2 strains are identical except for a region on chromosome 4, the a priori expectation is that only cisregulated genes located in that region of chromosome 4 or genes trans-regulated by genes within that region should differ. This is expected to be a small set of genes, the signal from which could be masked by random variations in the very large set of genes that do not differ. The genes within the QTL interval that differ in expression are by definition cis-regulated 
and thus QTG candidates. By focusing on the region that differed, and thereby limiting the number of comparisons and increasing the power of the analysis, we were able to detect differences in the expression of cis-regulated genes.

Analysis of all of the probe sets allows us to detect trans-regulated genes, but at the expense of reduced power due to the much larger number of comparisons and therefore higher FDR. As expected, nearly all of the genes that differed in expression in the analysis of all probe sets were located in the chromosome 4 region that differed, and are candidates for cis-acting QTGs.

The number of genes that differed in each individual region was not large. Many of the genes were differentially expressed (in the same direction) in more than 1 region; 3 (Ppm1k, LOC685879, and RGD1304879) in all 5 regions, 2 in 4 regions, and 2 in 3 regions. By combining the regions in a joint analysis, we were able to detect more differences (compare Tables 1 and 2). Many genes are expected to be expressed under similar regulatory control in different brain regions. This combined analysis has more power to detect genes that are changed in the same direction in multiple regions but might not meet the strict FDR within individual regions, because averaging the 5 individual measurements from each animal that contribute to the comparison reduces technical variation. When focusing on the genes within the QTL interval, 19 of the genes detected in individual regions were confirmed in the combined analysis and 15 additional genes were detected.

Nine genes were tested by qRT-PCR to confirm their differential expression; expression of 8 genes was in the expected direction, with 7 being significant at $p<0.005$. The exponential nature of the q-PCR reactions makes them less able to detect small differences in expression. The primers for these confirmation studies, when possible, were in the coding sequences spanning an intron. It has been our experience that when primers are designed based on the coding region, as we did here, the number of confirmed genes is lower than when using primers designed within the $3^{\prime}$ sequences used on the microarray chips. The overall level of confirmation is comparable to the FDR we had set $(<0.1)$.

The grouping of transcripts that were expressed higher or lower was evident when observed in their mapped positions (Fig. 1). One can speculate that these regions of up-regulation and down-regulation are due to transcriptional control by an epigenetic effect, such as methylation patterns and histone modification. Covalent modifications of histone proteins, RNA-associated gene silencing processes, and DNA methylation are components of the epigenetic mechanism controlling gene expression patterns. These modifications have the potential to work together to modify the spatial structure of the DNA and the chromatin associated with it, to establish structural states that are either favorable (open chromatin) or not favorable (closed chromatin) for gene expression (Callinan and Feinberg, 2006). Future experiments could examine epigenetic regulation.

Programs to classify genes into overrepresented categories are not powerful when dealing with small numbers of differentially expressed genes, as in this QTL study. Thus, for the purpose of the discussion, 5 categories (cell signaling, protein trafficking, synaptic function, metabolism, and gene expression) were selected based on the ontology of the differentially 
expressed genes in the chromosome 4 QTL region. In these categories, we discussed potential candidate genes that were detected in multiple brain regions and/or with multiple probe sets with at least a 15 to $20 \%$ difference in expression. We also discuss genes that have previously been implicated in alcohol preference.

Candidate genes involved in cell signaling include Dgki, BAI-associated protein 1 (Baiapl), and protein phosphatase type $1 \mathrm{~K}(P p m l k)$. DGKs are a family of enzymes that regulate the levels of various pools of diacylglycerol (DAG), affecting DAG-mediated signal transduction. Dgki catalyzes the phosphorylation of DAG, an activator of protein kinase C, to phosphatidic acid (PA) and thus down-regulates second messenger pathways activated by protein kinase C (Van Blitterswijk and Houssa, 1999), which play important roles in regulating behavioral responses to ethanol (Newton and Messing, 2006). The highest expression of Dgki, when studied in humans, is found in the brain (Ding et al., 1998); we found that it was expressed at higher levels in the NP.P brain regions compared with the iNP brain regions. This is similar to findings in the alcohol-accepting (AA) and alcoholnonaccepting (ANA) animals selectively bred for alcohol preference from Wistar stock, where $D g k i$ is expressed at higher levels in discrete brain regions of the AA compared with the ANA animals (Sommer et al., 2001).

Baiapl is a novel member of the membrane-associated guanylate kinase (MAGUK) homolog family and an isoform of the neurone-specific synaptic scaffolding molecule (SSCAM), which is known to interact with NMDA and delta 2 glutamate receptors (Grid2) (Dobrosotskaya et al., 1997); Grid2 was expressed at lower levels in the frontal cortex, amygdala, and combined analysis presented here (Tables 1 and 2). Membrane-associated guanylate kinase proteins participate in the assembly of multiprotein complexes on the inner surface of the plasma membrane at regions of cell-cell contact. Membrane-associated guanylate kinase proteins share a common modular structure that consists of multiple PDZ domains and a C-terminal guanylate kinase domain (Fanning and Anderson, 1999). They appear to have both structural and signaling roles within the cell and aid in localizing and coupling components of specific signal transduction pathways at specific subcellular locations. Another PDZ domain protein, multiple PDZ domain protein $(M p d z)$, has been identified as a QTG for alcohol and pentobarbital withdrawal seizures in mice (Shirley et al., 2004).

Ppmlk encodes a serine/threonine protein phosphatase. Together with protein kinases, these enzymes control the state of phosphorylation of cell proteins and thereby provide an important mechanism for regulating cellular activity.

Candidate genes involved in protein trafficking include Plexin A4 (Plxna4), sorting nexin 10 (Snx10), and src family-associated phosphoprotein 2 (Scap2). Plxna4 mediates multiple semaphorin signals, which are important in the development of the nervous system (Suto et al., 2005), and plays roles in a wide variety of axon guidance events in a highly regulated manner (Ben-Zvi et al., 2006). The protein Scap2 is an src-kinase associated protein. It plays a role in regulating the phosphorylation of Snca (Takahashi et al., 2003), a previously identified candidate gene for alcohol consumption in the iP/iNP animals. 
The candidate gene, glutamate receptor ionotropic delta 2 (Grid2), is involved in signal transduction and synaptic function. The Grid 2 gene encodes the ionotropic glutamate receptor channel delta- 2 subunit, functionally related to the amino-methylisoxazoleproprionate (AMPA) receptor (Landsend et al., 1997). Mutated Grid2 has an increased permeability to glutamate in Xenopus oocytes (Taverna et al., 2000) and to calcium in HEK 293 cells (Wollmuth et al., 2000). Grid2 is located within a common fragile site (CFS), which is a large region of genomic instability found in all individuals (Smith et al., 2006), making it an especially likely target for mutations involving genetic rearrangement (Robinson et al., 2005). Many of the large CFS genes, greater than 99\% intronic, are involved in neurological development. Whether there are instability-induced alterations in the iP/iNP Grid 2 gene that influence its expression and in turn play a role in alcohol preference will require further investigation.

Candidate genes involved in metabolism include aldoketo reductase 1, member B4 (Akrlb4), and Akrlb10. Aldo-keto reductases catalyze the reduction of aliphatic and aromatic aldehydes to their corresponding alcohols.

Candidate genes involved in gene expression include zinc finger protein 398 and juxtaposed with another zinc finger protein 1. Many zinc finger proteins bind nucleic acids and regulate transcription.

Two previously identified candidate genes for alcohol preference, Npy and Snca, differed in expression when the data from the 5 discrete brain regions of each animal were averaged (Table 2). Npy expression was lower in the congenics than in the iNP animals; it was previously shown to be lower in iP than in iNP (Spence et al., 2005). The expression of Snca was lower in the congenic animals compared with the iNP animals (Table 2), whereas previous studies of the iP versus iNP showed higher expression in the iP animals (Liang et al., 2003), suggesting that Snca may be more prominently regulated by trans-regulatory than cis-regulatory factors.

The changes that were detected were small: only 10 of the 35 genes differed more than $20 \%$ (Table 2). Other comparisons of brain expression have also reported small differences. In a study that identified differentially expressed genes between the AA and ANA rat lines, the majority of differences reported were less than 50\% (Worst et al., 2005). Likewise, most of the differences in expression levels in the hippocampi of iP and iNP alcohol-naïve rats were less than 50\% (Edenberg et al., 2004). In another study, brain gene expression differences between the C57BL/6 and DBA/2 mice within QTL were compared; again, most of the differences were small (Hitzemann et al., 2004).

In summary, very interesting candidate genes and possible pathways have been identified by expression profiling of the congenic NP.P strain. The alteration in expression of $D g k i$ (down-regulates PKC), Grid2 (phosphorylated by PKC), Scap2 (inhibits phosphorylation), and Ppmlk (serine/threonine phosphatase) strongly suggests that signal transduction pathways, especially the PKC pathway, are involved in the development of alcohol preference in the iP rats. Thus, the findings from this study provide interesting candidate genes for future functional and knockout studies, and information to other investigators who 
are using these animals to study weight, anxiety (personal communication), bone mass, and bone strength (Alam et al., 2005).

\section{Acknowledgments}

This work was supported by the National Institute on Alcohol Abuse and Alcoholism Grants AA10707 and AA07611. The microarray studies were carried out using the facilities of the Center for Medical Genomics at Indiana University School of Medicine. The Center for Medical Genomics is supported in part by the Indiana Genomics Initiative of Indiana University, INGEN, which is supported in part by the Lilly Endowment Inc.

\section{References}

Alam I, Robling AG, Weissing S, Carr LG, Lumeng L, Turner CH. Bone mass and strength: phenotypic and genetic relationship to alcohol preference in P/NP and HAD/LAD rats. Alcohol Clin Exp Res. 2005; 29:1769-1776. [PubMed: 16269906]

Barrett T, Suzek TO, Troup DB, Wilhite SE, Ngau WC, Ledoux P, Rudnev D, Lash AE, Fujibuchi W, Edgar R. NCBI GEO: mining millions of expression profiles-database and tools. Nucleic Acids Res. 2005; 33:D562-D566. [PubMed: 15608262]

Benjamini Y, Hochberg Y. Controlling the false discovery rate: a practical and powerful approach to multiple testing. J R Stat Soc (B). 1995; 57:289-290.

Ben-Zvi A, Yagil Z, Hagalili Y, Klein H, Lerman O, Behar O. Semaphorin 3A and neurotrophins: a balance between apoptosis and survival signaling in embryonic DRG neurons. J Neurochem. 2006; 96:585-597. [PubMed: 16336628]

Bice P, Foroud T, Bo R, Castelluccio P, Lumeng L, Li TK, Carr LG. Genomic screen for QTLs underlying alcohol consumption in the P and NP rat lines. Mamm Genome. 1998; 9:949-955. [PubMed: 9880658]

Bolstad BM, Irizarry RA, Astrand M, Speed TP. A comparison of normalization methods for high density oligonucleotide array data based on variance and bias. Bioinformatics. 2003; 19:185-193. [PubMed: 12538238]

Bonci A, Bernardi G, Grillner P, Mercuri NB. The dopamine-containing neuron: maestro or simple musician in the orchestra of addiction? Trends Pharmacol Sci. 2003; 24:172-177. [PubMed: 12707003]

Callinan PA, Feinberg AP. The emerging science of epigenomics. Hum Mol Genet. 2006; 15(Spec No 1):R95-R101. [PubMed: 16651376]

Carr LG, Foroud T, Bice P, Gobbett T, Ivashina J, Edenberg H, Lumeng L, Li TK. A quantitative trait locus for alcohol consumption in selectively bred rat lines. Alcohol Clin Exp Res. 1998; 22:884887. [PubMed: 9660316]

Carr LG, Habegger K, Spence JP, Liu L, Lumeng L, Li TK, Foroud T. Development of congenic rat strains for alcohol preference derived from the alcohol-preferring and -nonpreferring rats. Behav Genet. 2006; 36:285-290. [PubMed: 16470346]

Cicero, TJ. A critique of animal analogues of alcoholism. In: Majchrowicz, E.; Noble, EP., editors. Biochemistry and Pharmacology of Ethanol. Vol. 2. Plenum Press; New York: 1979. p. 533-560.

Covault J, Gelernter J, Hesselbrock V, Nellissery M, Kranzler HR. Allelic and haplotypic association of GABRA2 with alcohol dependence. Am J Med Genet B Neuropsychiatr Genet. 2004; 129:104109. [PubMed: 15274050]

Ding L, Traer E, McIntyre TM, Zimmerman GA, Prescott SM. The cloning and characterization of a novel human diacylglycerol kinase, DGKiota. J Biol Chem. 1998; 273:32746-32752. [PubMed: 9830018]

Dobrosotskaya I, Guy RK, James GL. MAGI-1, a membrane-associated guanylate kinase with a unique arrangement of protein-protein interaction domains. J Biol Chem. 1997; 272:31589-31597. [PubMed: 9395497]

Edenberg HJ, Dick DM, Xuei X, Tian H, Almasy L, Bauer LO, Crowe RR, Goate A, Hesselbrock V, Jones K, Kwon J, Li TK, Nurnberger JI Jr, O’Connor SJ, Reich T, Rice J, Schuckit MA, Porjesz B, Foroud T, Begleiter H. Variations in GABRA2, encoding the alpha 2 subunit of the GABA(A) 
receptor, are associated with alcohol dependence and with brain oscillations. Am J Hum Genet. 2004; 74:705-714. [PubMed: 15024690]

Edenberg HJ, Strother WN, McClintick JN, Tian H, Stephens M, Jerome RE, Lumeng L, Li TK, McBride WJ. Gene expression in the hippocampus of inbred alcohol-preferring and -nonpreferring rats. Genes Brain Behav. 2005; 4:20-30. [PubMed: 15660665]

Edenberg HJ, Xuei X, Chen HJ, Tian H, Wetherill LF, Dick DM, Almasy L, Bierut L, Bucholz KK, Goate A, Hesselbrock V, Kuperman S, Nurnberger J, Porjesz B, Rice J, Schuckit M, Tischfield J, Begleiter H, Foroud T. Association of alcohol dehydrogenase genes with alcohol dependence: a comprehensive analysis. Hum Mol Genet. 2006; 15:1539-1549. [PubMed: 16571603]

Edgar R, Domrachev M, Lash AE. Gene expression omnibus: NCBI gene expression and hybridization array data repository. Nucleic Acids Res. 2002; 30:207-210. [PubMed: 11752295]

Fanning AS, Anderson JM. PDZ domains: fundamental building blocks in the organization of protein complexes at the plasma membrane. J Clin Invest. 1999; 103:767-772. [PubMed: 10079096]

Fehr C, Sander T, Tadic A, Lenzen KP, Anghelescu I, Klawe C, Dahmen N, Schmidt LG, Szegedi A. Confirmation of association of the GABRA2 gene with alcohol dependence by subtype-specific analyses. Psychiatr Genet. 2006; 16:9-17. [PubMed: 16395124]

Gentleman RC, Carey VJ, Bates DM, Bolstad B, Dettling M, Dudoit S, Ellis B, Gautier L, Ge Y, Gentry J, Hornik K, Hothorn T, Huber W, Iacus S, Irizarry R, Leisch F, Li C, Maechler M, Rossini AJ, Sawitzki G, Smith C, Smyth G, Tierney L, Yang JY, Zhang J. Bioconductor: open software development for computational biology and bioinformatics. Genome Biol. 2004; 5:R80. [PubMed: 15461798]

Guindalini C, Scivoletto S, Ferreira RG, Breen G, Zilberman M, Peluso MA, Zatz M. Association of genetic variants in alcohol dehydrogenase 4 with alcohol dependence in Brazilian patients. Am J Psychiatr. 2005; 162:1005-1007. [PubMed: 15863808]

Hitzemann R, Reed C, Malmanger B, Lawler M, Hitzemann B, Cunningham B, McWeeney S, Belknap J, Harrington C, Buck K, Phillips T, Crabbe J. On the integration of alcohol-related quantitative trait loci and gene expression analyses. Alcohol Clin Exp Res. 2004; 28:1437-1448. [PubMed: 15597075]

Hoffman P, Tabakoff B. Gene expression in animals with different acute responses to ethanol. Addict Biol. 2005; 10:63-69. [PubMed: 15849020]

Irizarry RA, Hobbs B, Collin F, Beazer-Barclay YD, Antonellis KJ, Scherf U, Speed TP. Exploration, normalization, and summaries of high density oligonucleotide array probe level data. Biostatistics. 2003; 4:249-264. [PubMed: 12925520]

Landsend AS, Amiry-Moghaddam M, Matsubara A, Bergersen L, Usami S, Wenthold RJ, Ottersen OP. Differential localization of delta glutamate receptors in the rat cerebellum: coexpression with AMPA receptors in parallel fiber-spine synapses and absence from climbing fiber-spine synapses. J Neurosci. 1997; 17:834-842. [PubMed: 8987804]

Lappalainen J, Krupitsky E, Remizov M, Pchelina S, Taraskina A, Zvartau E, Somberg LK, Covault J, Kranzler HR, Krystal JH, Gelernter J. Association between alcoholism and gamma-amino butyric acid alpha2 receptor subtype in a Russian population. Alcohol Clin Exp Res. 2005; 29:493-498. [PubMed: 15834213]

Li TK, Lumeng L, Doolittle DP. Selective breeding of alcohol preference and associated responses. Behav Genet. 1993; 23:163-170. [PubMed: 8099788]

Li TK, Lumeng L, Doolittle DP, Carr LG. Molecular associations of alcohol-seeking behavior in rat lines selectively bred for high and low voluntary ethanol drinking. Alcohol. 1991; (suppl 1):121124.

Liang T, Habegger K, Spence JP, Foroud T, Ellison JA, Lumeng L, Li TK, Carr LG. Glutathione-Stransferase 8-8 expression is lower in alcohol-preferring than alcohol-nonpreferring rats. Alcohol Clin Exp Res. 2004; 28:1622-1628. [PubMed: 15547447]

Liang T, Spence J, Liu L, Strother WN, Chang HW, Ellison JA, Lumeng L, Li TK, Foroud T, Carr LG. $a$-Synuclein maps to a QTL for alcohol preference and is differentially expressed in alcoholpreferring and -nonpreferring rats. PNAS. 2003; 100:4690-4695. [PubMed: 12665621] 
Luo X, Kranzler HR, Zuo L, Wang S, Blumberg HP, Gelernter J. CHRM2 gene predisposes to alcohol dependence, drug dependence and affective disorders: results from an extended case-control structured association study. Hum Mol Genet. 2005b; 14:2421-2434. [PubMed: 16000316]

Luo X, Kranzler HR, Zuo L, Yang BZ, Lappalainen J, Gelernter J. ADH4 gene variation is associated with alcohol and drug dependence: results from family controlled and population-structured association studies. Pharmacogenet Genomics. 2005a; 15:755-768. [PubMed: 16220108]

Maldonado R. The neurobiology of addiction. J Neural Transm Suppl. 2003; 66:1-14. [PubMed: 14582800]

McClintick JN, Edenberg HJ. Effects of filtering by present call on analysis of microarray experiments. BMC Bioinformat. 2006; 7:49.

Newton PM, Messing RO. Intracellular signaling pathways that regulate behavioral responses to ethanol. Pharmacol Ther. 2006; 109:227-237. [PubMed: 16102840]

R Development Core Team. R Foundation for Statistical Computing. R Development Core Team; Vienna, Austria: 2006. R: A language and environment for statistical computing.

Robinson KO, Petersen AM, Morrison SN, Elso CM, Stubbs L. Two reciprocal translocations provide new clues to the high mutability of the Grid2 locus. Mamm Genome. 2005; 16:32-40. [PubMed: 15674731]

Shirley RL, Walter NA, Reilly MT, Fehr C, Buck KJ. Mpdz is a quantitative trait gene for drug withdrawal seizures. Nat Neurosci. 2004; 7:699-700. [PubMed: 15208631]

Smith DI, Zhu Y, McAvoy S, Kuhn R. Common fragile sites, extremely large genes, neural development and cancer. Cancer Lett. 2006; 232:48-57. [PubMed: 16221525]

Smyth GK. Linear models and empirical Bayes methods for assessing differential expression in microarray experiments. Stat Appl Genet Mol Biol. 2004; 3:Article 3.

Sommer W, Arlinde C, Caberlotto L, Thorsell A, Hyytia P, Heilig M. Differential expression of diacylglycerol kinase iota and L18A mRNAs in the brains of alcohol-preferring AA and alcoholavoiding ANA rats. Mol Psychiatry. 2001; 6:103-108. [PubMed: 11244494]

Spence JP, Liang TB, Habegger K, Carr LG. Effect of polymorphism on expression of the NPY gene in inbred alcohol-preferring and -nonpreferring rats. Neuroscience. 2005; 131:871-876. [PubMed: 15749341]

Suto F, Ito K, Uemura M, Shimizu M, Shinkawa Y, Sanbo M, Shinoda T, Tsuboi M, Takashima S, Yagi T, Fujisawa H. Plexin-a4 mediates axon-repulsive activities of both secreted and transmembrane semaphorins and plays roles in nerve fiber guidance. J Neurosci. 2005; 25:36283637. [PubMed: 15814794]

Takahashi T, Yamashita H, Nagano Y, Nakamura T, Ohmori H, Avraham H, Avraham S, Yasuda M, Matsumoto M. Identification and characterization of a novel Pyk2/related adhesion focal tyrosine kinase-associated protein that inhibits alpha-synuclein phosphorylation. J Biol Chem. 2003; 278:42225-42233. [PubMed: 12893833]

Taverna ZG, Xiong L, Brandes JC, Roder MW, Salter MW, MacDonald JF. The Lurcher mutation of an alpha-amino-3-hydroxy-5-methyl-4-isoxazolepropionic acid receptor subunit enhances potency of glutamate and converts an antagonist to an agonist. J Biol Chem. 2000; 275:8475-8479. [PubMed: 10722683]

van Blitterswijk WJ, Houssa B. Diacylglycerol kinases in signal transduction. Chem Phys Lipids. 1999; 98:95-108. [PubMed: 10358932]

Wang JC, Hinrichs AL, Stock H, Budde J, Allen R, Bertelsen S, Kwon JM, Wu W, Dick DM, Rice J, Jones K, Nurnberger JI Jr, Tischfield J, Porjesz B, Edenberg HJ, Hesselbrock V, Crowe R, Schuckit M, Begleiter H, Reich T, Goate AM, Bierut LJ. Evidence of common and specific genetic effects: association of the muscarinic acetylcholine receptor M2 (CHRM2) gene with alcohol dependence and major depressive syndrome. Hum Mol Genet. 2004; 13:1903-1911. [PubMed: 15229186]

Wollmuth LP, Kuner T, Jatzke C, Seeburg PH, Heintz N, Zuo J. The Lurcher mutation identifies delta 2 as an AMPA/kainate receptor-like channel that is potentiated by $\mathrm{Ca}(2+)$. J Neurosci. 2000; 20:5973-5980. [PubMed: 10934245] 
Worst TJ, Tan JC, Robertson DJ, Freeman WM, Hyytia P, Kiianmaa K, Vrana KE. Transcriptome analysis of frontal cortex in alcohol-preferring and nonpreferring rats. J Neurosci Res. 2005; 80:529-538. [PubMed: 15846778] 

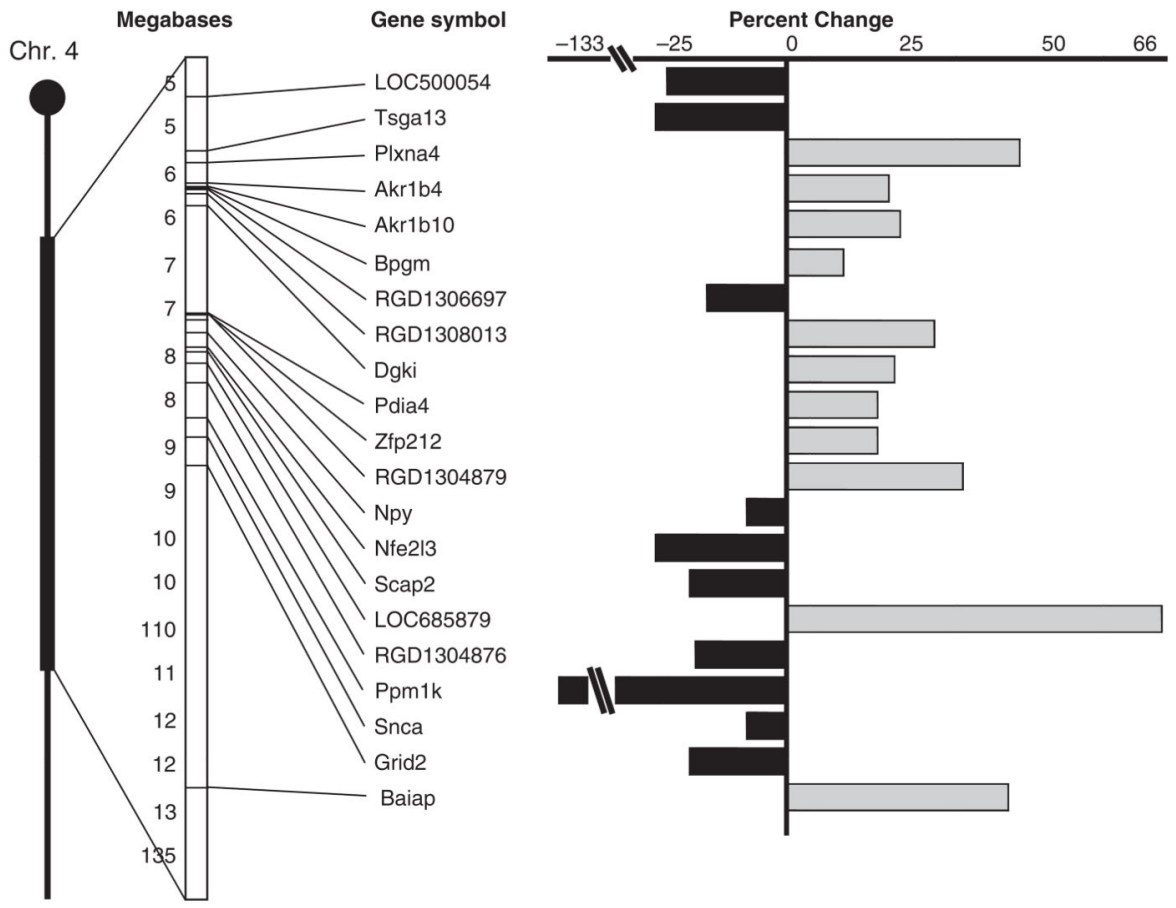

Fig. 1.

Mapping of the genes differentially expressed between the NP.P congenic strain and the iNP strain. The thick line on the left designates the $\mathrm{Chr} 4$ quantitative trait locus region. Gene symbols and their physical locations (megabases) are on the left and the percent difference and direction are on the right. 


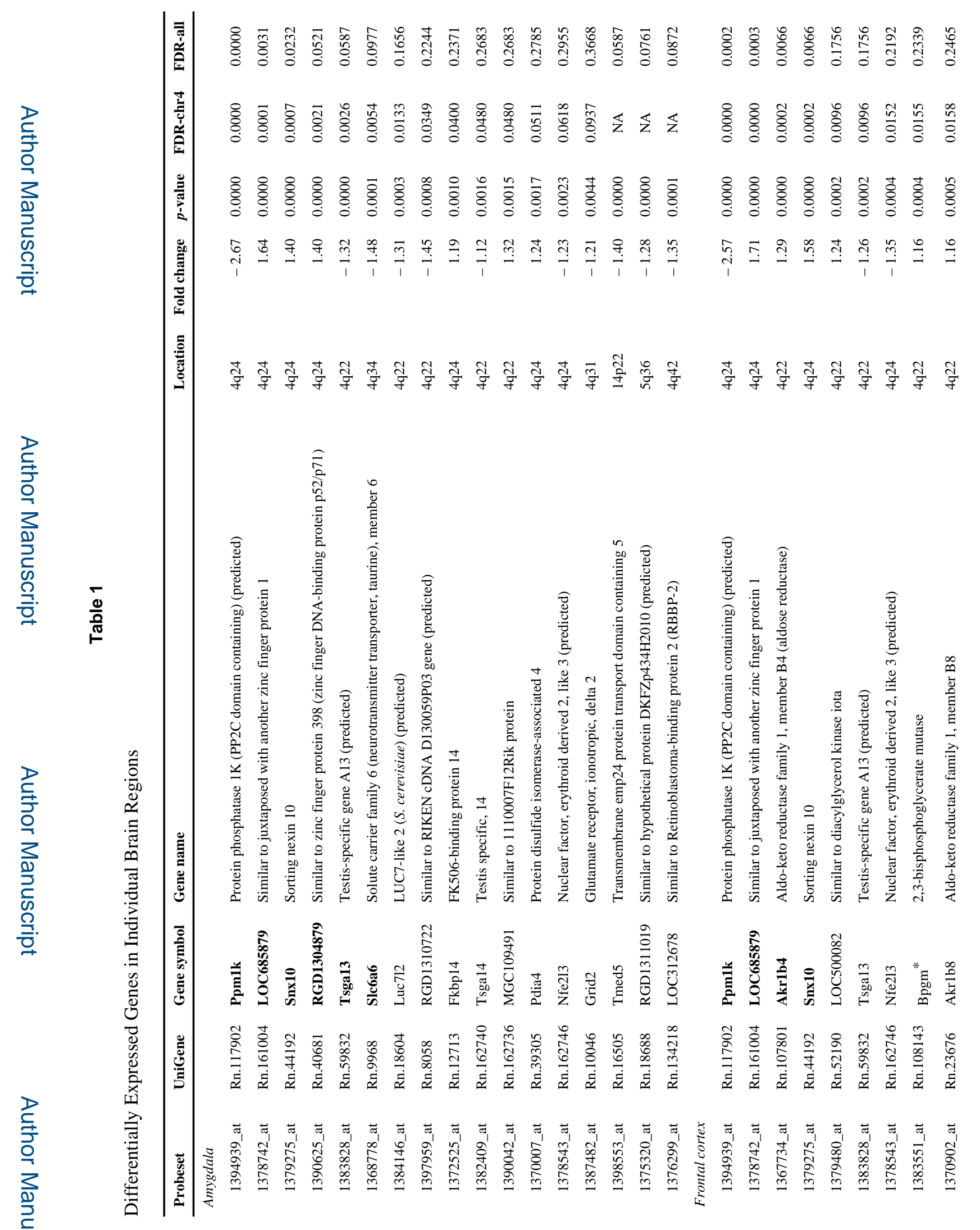

Alcohol Clin Exp Res. Author manuscript; available in PMC 2015 June 04. 


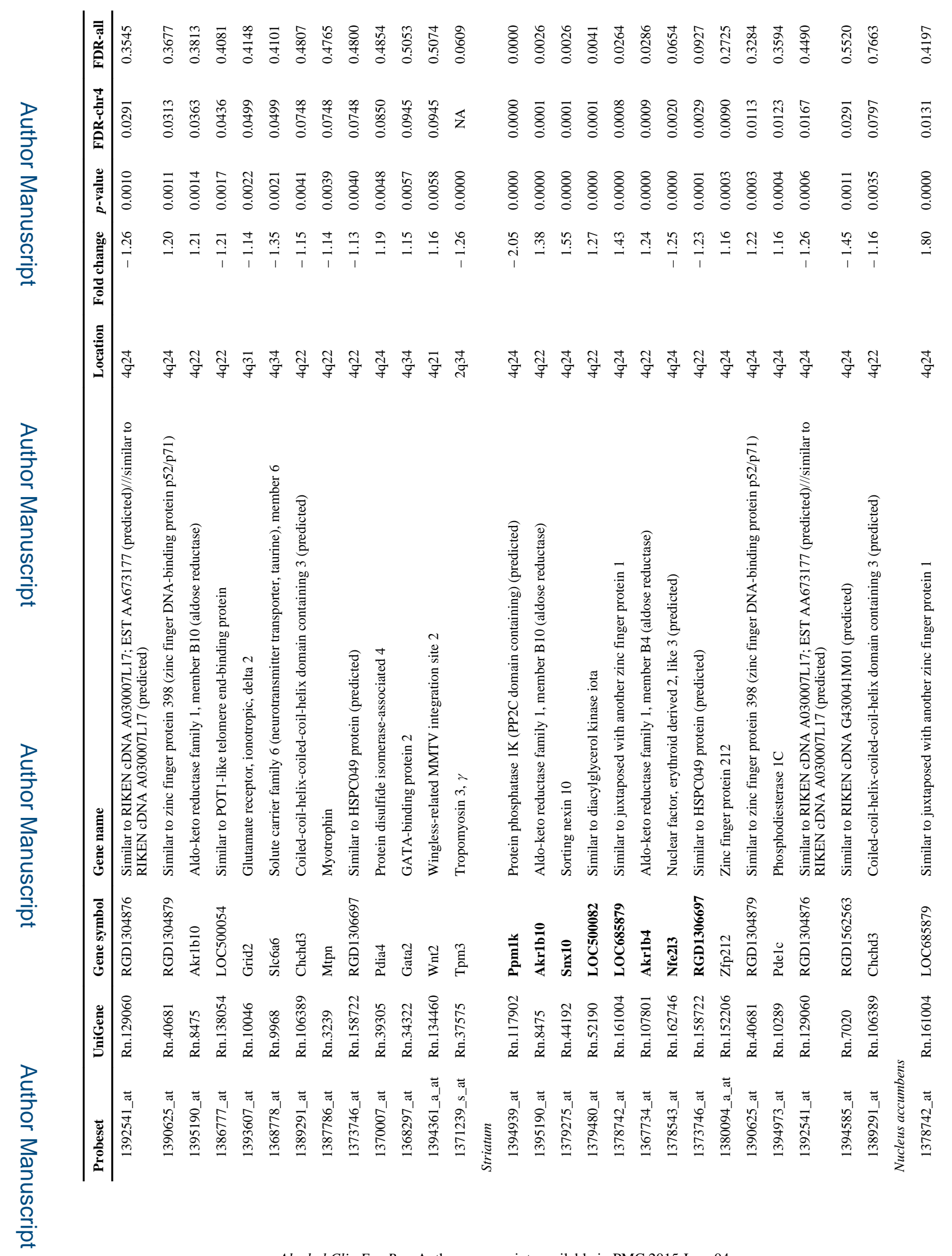

Alcohol Clin Exp Res. Author manuscript; available in PMC 2015 June 04. 
Carr et al.

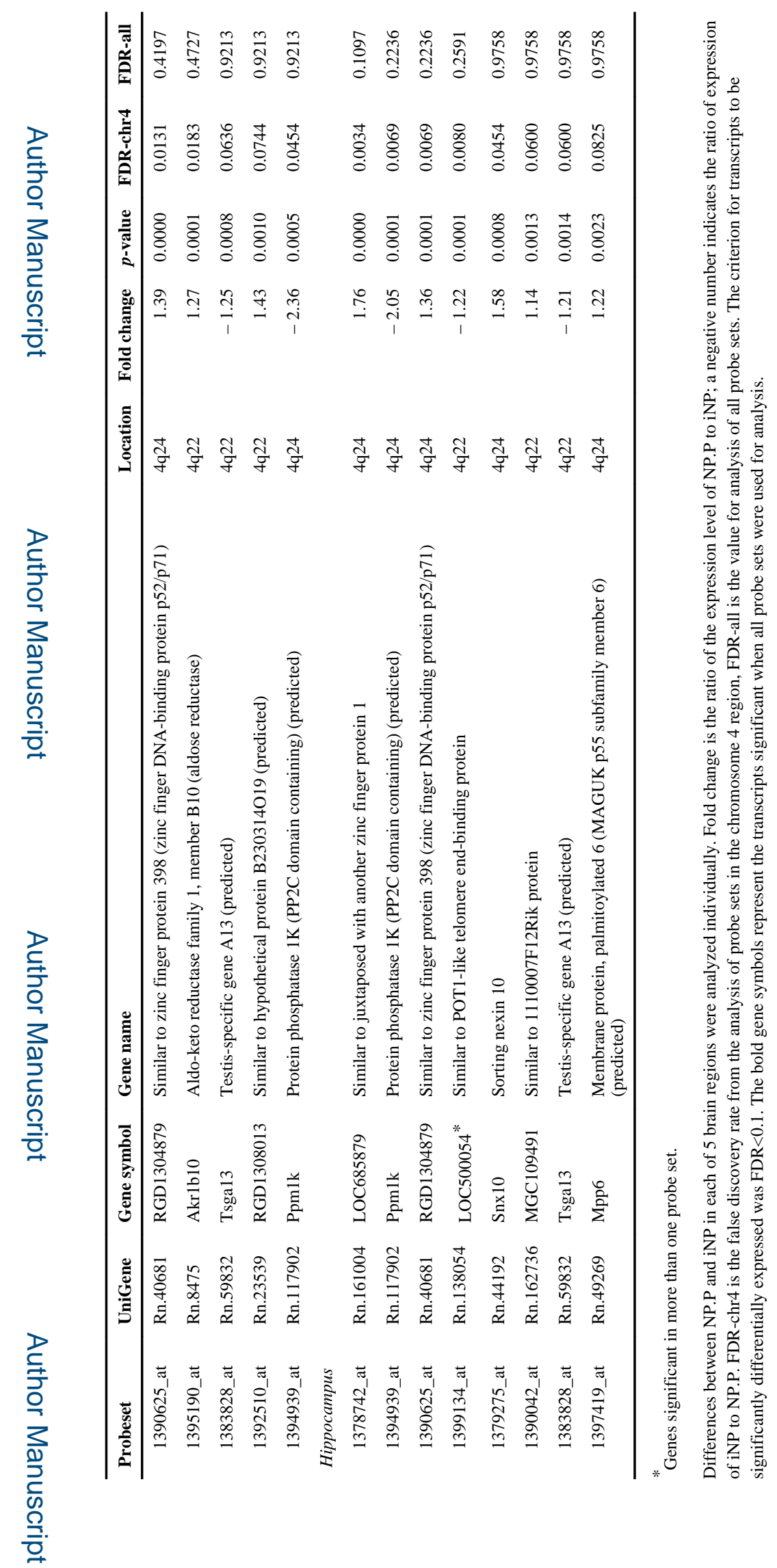

Alcohol Clin Exp Res. Author manuscript; available in PMC 2015 June 04. 


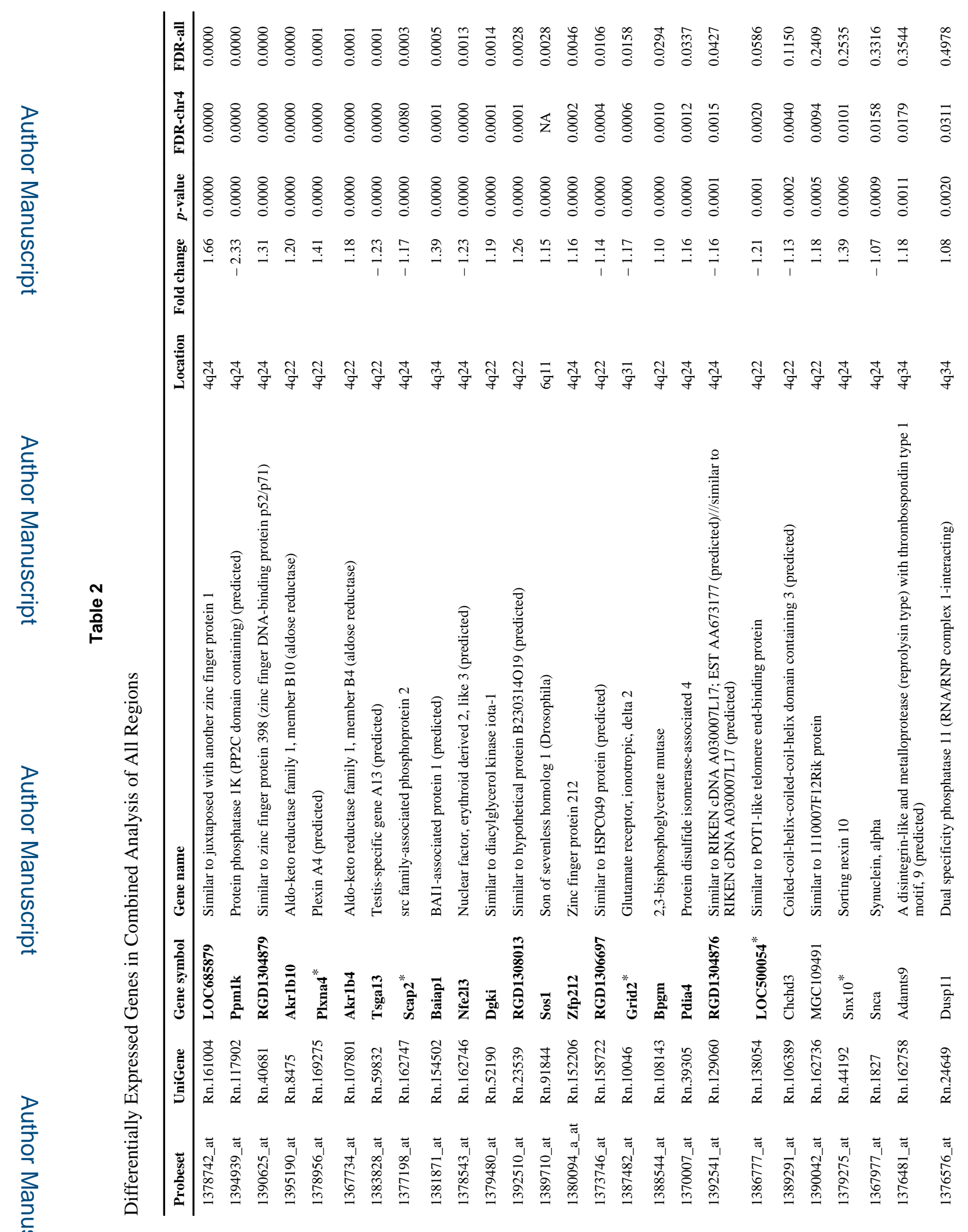

Alcohol Clin Exp Res. Author manuscript; available in PMC 2015 June 04. 
Carr et al.

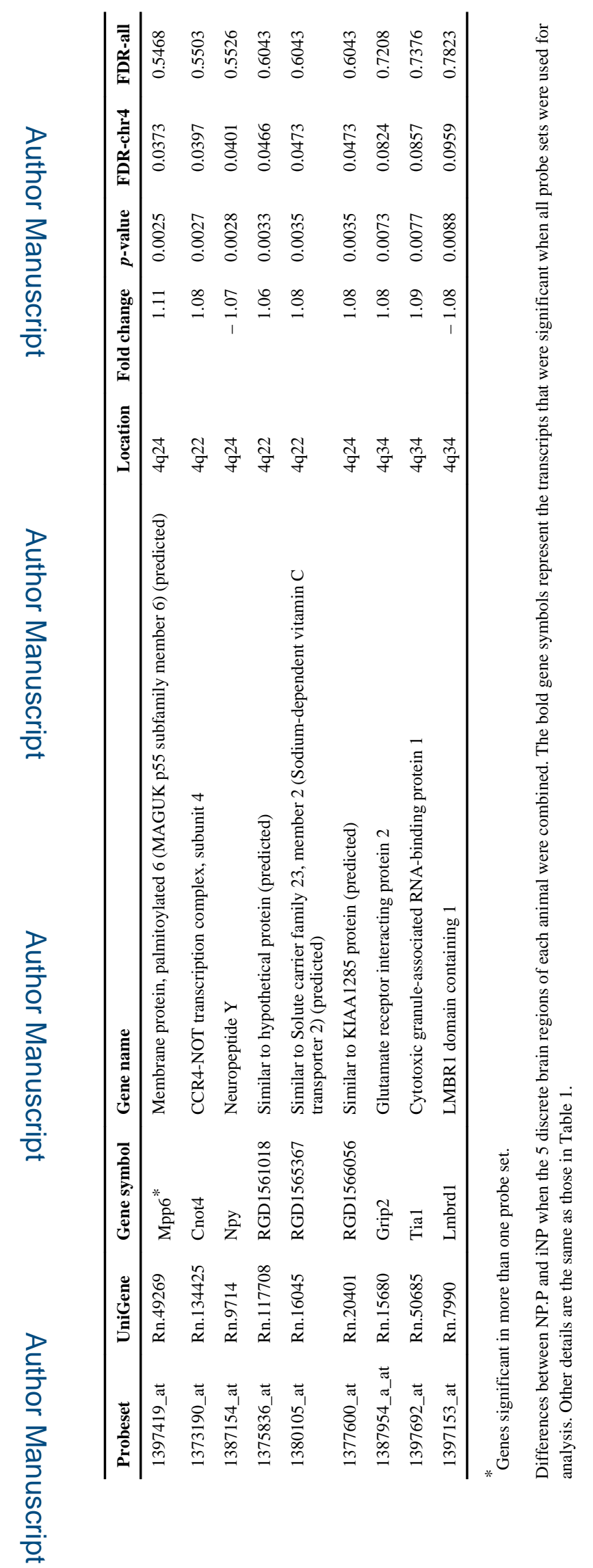

Alcohol Clin Exp Res. Author manuscript; available in PMC 2015 June 04. 


\section{Table 3}

qRT-PCR Confirmation of Microarray Data

\begin{tabular}{lrc}
\hline & \multicolumn{2}{c}{ Fold change $^{a}$} \\
\cline { 2 - 3 } Gene name & Microarray & qRT-PCR \\
\hline Akr1b4 & 1.18 & $1.28^{b}$ \\
Baiap & 1.39 & $1.67^{b}$ \\
Dgki & 1.19 & $2.19^{b}$ \\
Ppm1K & -2.33 & $-1.83^{b}$ \\
Snca & -1.07 & $-1.48^{b}$ \\
Grid2 & -1.17 & $-1.64^{b}$ \\
Sos1 & 1.15 & 1.05 \\
Npy & -1.07 & -1.04 \\
Zfp212 & 1.16 & $-1.82^{c}$ \\
\hline
\end{tabular}

${ }^{a}$ Fold change is the ratio of the expression level of NP.P to iNP; a negative number indicates the ratio of expression of iNP to NP.P.

${ }^{b}$ Fold change for qRT-PCR is significant at $p<0.005$.

${ }^{c}$ Fold change is significant, but not in the expected direction. 